\title{
Fibroma de fibroblastos gigantes. Presentación de 122 casos.
}

\author{
Giant Cell filoroma. Presentation of 122 cases. \\ Lizette Ariza Ramírez,* Beatriz Catalina Aldape Barrios ${ }^{\ddagger}$
}

\section{RESUMEN}

El fibroma de fibroblastos gigantes (FFG), conocido también como fibroma de células gigantes, es una pápula o nódulo asintomático localizado en la encía, paladar y lengua, es del mismo color que la mucosa adyacente, de base sésil o pediculada, con superficie lisa o papilar que por lo general mide menos de $1 \mathrm{~cm}$. Objetivo: Identificar las características demográficas e histopatológicas de los casos de FFG de un laboratorio privado de patología bucal en la Ciudad de México. Material y métodos: Se obtuvieron los datos de edad, sexo, diagnóstico presuntivo y definitivo de 122 casos de FFG de 2004 a 2019 con un total de 7,681 muestras. Se describe su distribución por edad, sexo y localización. Resultados: El rango de edad obtenido es de 1 a 84 años, con un promedio de $\mathrm{X}=38$ años, se presenta con mayor frecuencia en la segunda década de vida, con una razón de 1.6:1 mujer a hombre. La localización más frecuente es en lengua (46\%); sin embargo, sólo $49.1 \%$ de los estudios especificaban este dato. Conclusión: La importancia de esta lesión es que clínicamente se parece a otras patologías de tejido fibroso, por lo tanto, se debe tener presente al FFG como diagnóstico diferencial.

Palabras clave: Fibroma de fibroblastos gigantes, fibroma de células gigantes, histopatología.

\section{ABSTRACT}

Giant cell fibroma (GCF) is an asymptomatic papule or nodule that is similar in color to the surrounding mucosa, with a sessile or pedunculated base. It is usually less than $1 \mathrm{~cm}$ in size and it features a smooth or papillary surface. Objective: To identify the demographic and histopathological characteristics of GCF cases in a private oral pathology laboratory in Mexico City. Material and methods: Data on age, sex, as well as on presumptive and definitive diagnosis of $122 \mathrm{GCF}$ cases were obtained from 2004 to 2019 with a total of 7,681 samples. Its distribution by age, sex and localization is described. Results: The age range obtained is from 1 to 84 years, with a mean age of 38 years. Frequently during the second decade of life, the female to male ratio is 1.6:1. The most frequent location is the tongue (46\%), however, only 60 of 122 studies specified this data. Conclusion: Since this lesion clinically resembles another fibrous tissue pathology, it is warranted to have prior knowledge on its clinical characteristics, as GCF should be regarded as a differential diagnosis.

Keywords: Giant cell fibroblasts, giant cell fibroma, histopathology.

\section{INTRODUCCIÓN}

$\mathrm{E}^{\prime}$ I fibroma de fibroblastos gigantes (FFG) fue descrito por primera vez por Weathers y Callihan en 1974, se examinaron más de 2,000 muestras de hiperplasias fibrosas, 108 coincidieron con las características histopatológicas: presencia de numerosos fibroblastos gigantes con prolongaciones citoplasmáticas, mononucleados o binucleados, en forma de «mantarraya». ${ }^{1}$ El FFG representa aproximadamente de 2 a $5 \%$ de todas las biopsias bucales de tejido fibroso y de 0.4 a $1 \%$ del total de resultados histopatológicos, ${ }^{2}$ es referido como una neoplasia por Gnepp ${ }^{3}$ y Neville, ${ }^{2}$ mientras que para Regezi, ${ }^{4}$ Reibel, ${ }^{5}$ Savage ${ }^{6}$ y Magnusson ${ }^{7}$ su origen es reactivo.

Se presenta como un nódulo o pápula, del mismo color que la mucosa adyacente, de base sésil o pediculada, por lo general mide menos de $1 \mathrm{~cm}$, con superficie lisa o papilar, que puede asemejarse a un papiloma, tiene

\footnotetext{
* Cirujano Dentista, privado.

‡ Maestra, Facultad de Odontología de la Universidad Nacional Autónoma de México. Ciudad de México, México.

Recibido: 28 de julio de 2020. Aceptado: 26 de enero de 2021.

Citar como: Ariza RL, Aldape BBC. Fibroma de fibroblastos gigantes. Presentación de 122 casos. Rev ADM. 2021 ; 78 (1): 7-12. https://dx.doi. org/10.35366/98381
} 
un rango de seis a 67 años; ${ }^{8}$ sin embargo, alrededor de $60 \%$ de los casos son diagnosticados en las primeras tres décadas de la vida, con un promedio de edad de 29 años, ${ }^{9}$ en comparación con el fibroma de origen reactivo que se presenta con mayor frecuencia en la cuarta a sexta década. ${ }^{2}$ Neville $^{2}$ menciona que $50 \%$ de todos los casos se localizan en la encía, mientras que $\mathrm{Woo}^{10}$ reporta que en $90 \%$ de los casos la más afectada es la encía mandibular, otras localizaciones comunes son la lengua y el paladar. ${ }^{2}$

En cuanto a la distribución por género hay resultados variables: Houston, ${ }^{11}$ Campos $^{12}$ y Neville ${ }^{2}$ reportan una razón de 1.5:1 mujer a hombre; Okamura ${ }^{13}$ indica una menor diferencia de 1.2:1 mujer a hombre; Sabarinath ${ }^{8}$ obtiene una ligera predilección por el sexo masculino, 1:1.3 mujer a hombre; mientras que Magnusson ${ }^{7}$ y Sonalika ${ }^{14}$ registran una misma razón para ambos sexos; no obstante, Reibel $^{5}$ menciona en su estudio que no hay predilección significativa por algún sexo.

La presencia de células inflamatorias fundamenta que la lesión sea reactiva, aunque la inflamación puede ocurrir secundario al desarrollo neoplásico de la lesión. Reibe ${ }^{5}$ y Magnusson ${ }^{7}$ reportan que se ha considerado que el granuloma piógeno podría ser la lesión primaria y el FFG es la entidad madura de ésta, lo que indicaría que las células gigantes provienen del endotelio; sin embargo, los fibroblastos gigantes resultan negativos para factor VII y lectina. Anteriormente, cuando Weathers y Callihan ${ }^{1}$ reportaron por primera vez esta patología, sugirieron que las células gigantes podrían ser melanocitos o células de Langerhans, teoría que fue apoyada por Houston en $1982,{ }^{11}$ pero futuras investigaciones realizadas por Odell, ${ }^{15}$ Magnusson $^{7}$ y Campos $^{2}$ mencionan que las células son negativas para S-100. Odell ${ }^{16}$ y Magnusson ${ }^{7}$ mostraron en sus trabajos con técnica de inmunohistoquímica reactividad negativa para citoqueratinas, neurofilamento, HHF35, CD68, HLADR y triptasa. Asimismo, Campos ${ }^{12}$ en su estudio refiere que las células son negativas para actina- $\alpha$ de músculo liso, desmina, LCA y HLA-DR, por lo que su origen no es endotelial ni miofibroblástico y no pertenecen al de linaje monocito-macrófago. Por otra parte, Magnusson ${ }^{7}$ Odell ${ }^{15}$ y Bakos ${ }^{17}$ demostraron que son positivas para vimentina y prolil-4-hidroxilasa, por lo tanto, las células gigantes, estrelladas y multinucleadas ${ }^{18}$ del FFG tienen fenotipo de fibroblastos. ${ }^{19,20}$

El análisis inmunohistoquímico realizado por Mighell ${ }^{21}$ ha mostrado positividad para el antígeno nuclear de células en proliferación (PCNA), pero para Ki-67 fue negativo, lo que indica que la mitosis sin citocinesis no está involucrada en la formación de células gigantes del FFG; por tanto, la hipótesis alternativa de la formación de células gigantes multinucleadas a través de la fusión celular podría ser el mecanismo de histogénesis en los casos de FFG, pero se necesita confirmación. ${ }^{21}$

Clínicamente puede tener diversos diagnósticos diferenciales, ya que su apariencia y localización es muy similar a otras (Figura 1). El diagnóstico definitivo se realiza por medio del examen histopatológico, en el cual se espera encontrar tejido conectivo con la característica distintiva que es la presencia de numerosos fibroblastos gigantes, estelares, mononucleados o binucleados, en forma de mantarraya, dentro de la lámina propia superficial. 2,10

El tratamiento de elección para el FFG es la escisión quirúrgica completa de la lesión, ya sea por medios convencionales o por electrocirugía, ${ }^{2}$ las recidivas se han reportado sólo en casos solitarios. ${ }^{2,9,11,17}$ A pesar de esto, las citas de seguimiento son necesarias para garantizar la ausencia de recidiva. En caso de que la lesión no sea tratada puede continuar creciendo, pero con un potencial de crecimiento limitado por su naturaleza benigna. El FFG, comparado con otras lesiones gingivales como el fibroma osificante periférico, no provocan el desplazamiento de los dientes o la reabsorción interdental de la cresta alveolar. ${ }^{22,23}$

Objetivo: Identificar las características demográficas e histopatológicas de 122 casos de FFG en un centro histopatológico privado en la Ciudad de México, durante el periodo de 2004 a 2019, con una población estudio de 7,681 muestras.

\section{MATERIAL Y MÉTODOS}

Criterios de inclusión: casos reportados con diagnóstico histopatológico de FFG que cuenten con los datos de edad, sexo, diagnóstico clínico y la laminilla histológica correspondiente.

Criterios de exclusión: casos que no correspondan a los años estipulados y aquellas laminillas que no se pudieron revisar.

Variable dependiente: diagnóstico presuntivo y diagnóstico histopatológico.

Variables independientes: edad, sexo y localización.

A través de un estudio transversal descriptivo se identificaron las características demográficas e histopatológicas de 122 casos de FFG en un centro histopatológico privado en la Ciudad de México, durante el periodo de 2004 a 2019. Las muestras estudiadas fueron teñidas con hematoxilina-eosina, se utilizó un microscopio óptico con objetivos de $4 \times, 10 \times$ y $40 \times$. Las características histopatológicas que se registraron fueron la presencia de fibroblastos gigantes estelares en forma de mantarraya, 
en un tejido conectivo fibroso denso bien vascularizado, revestido por epitelio escamoso estratificado paraqueratinizado (Figura 2).

\section{RESULTADOS}

Los resultados indican un rango de edad de 1 a 84 años; no obstante, se presenta con mayor frecuencia para ambos sexos en la segunda década de vida con $18.4 \%$, de ese porcentaje $9.2 \%$ corresponde a hombres y $9.2 \%$ a mujeres; a su vez, ésta es la década con mayor frecuencia en varones. En mujeres es en la quinta con $15.5 \%$ y $2 \%$ en hombres (Figura 3). En 120 casos de 122 se reportó el sexo, la prevalencia registrada entre ambos sexos es mayor por el sexo femenino: 75 mujeres $(62.5 \%)$ y 45 hombres (37.5\%). Se obtuvo una razón mujer a hombre de 1.6:1. Las muestras se enviaron con 18 diagnósticos presuntivos diferentes; sin embargo, los de mayor frecuencia son: hiperplasia fibrosa (44 casos), fibroma (26 casos) y papiloma (11 casos) (Tabla 1). Sólo un caso fue referido como FFG; se asume que el profesional tiene conocimiento de la lesión, debido a que cumple con las características clínicas de esta patología. Únicamente en 60 casos (49.1\%) de 122 se registraron los datos de localización, las más frecuentes fueron en lengua (46\%), encía (15\%) y paladar (15\%).

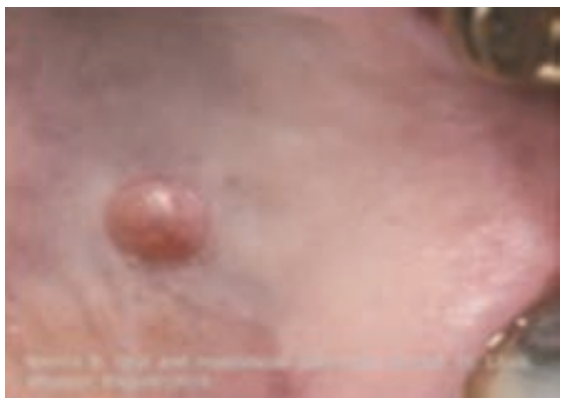

Neuroma

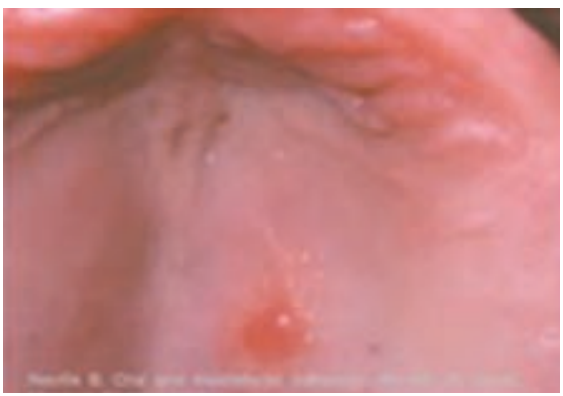

Leiomioma

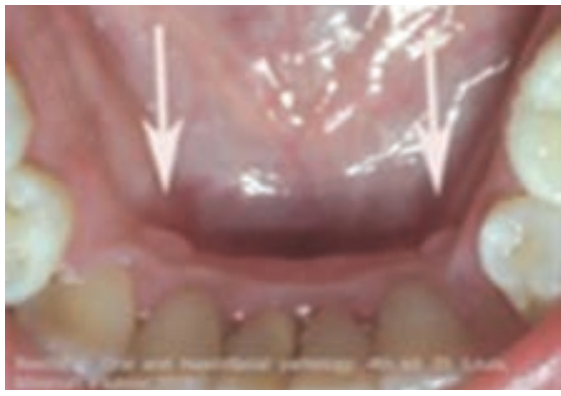

Papila retrocuspídea

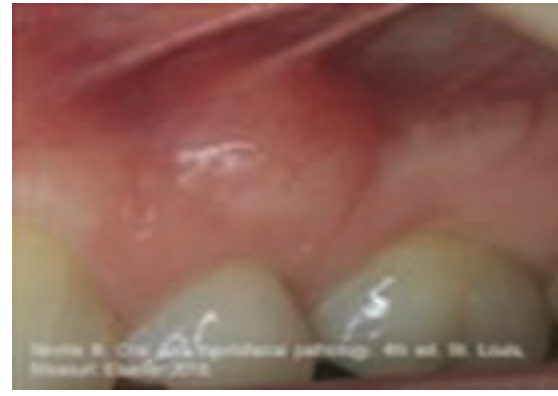

Neurofibroma

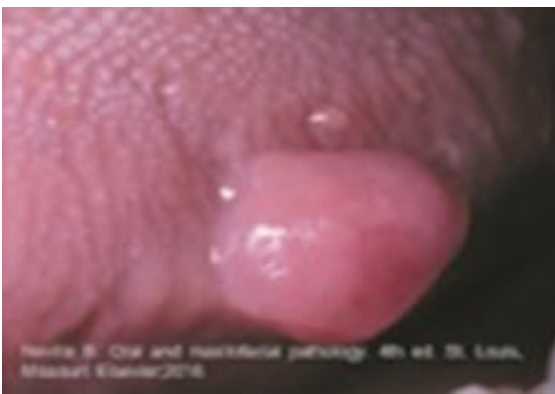

Fibroma

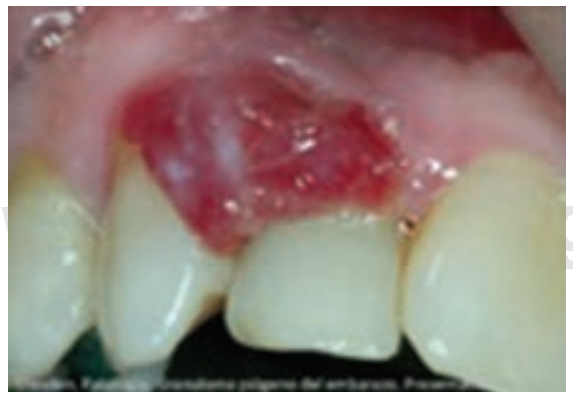

Granuloma piógeno

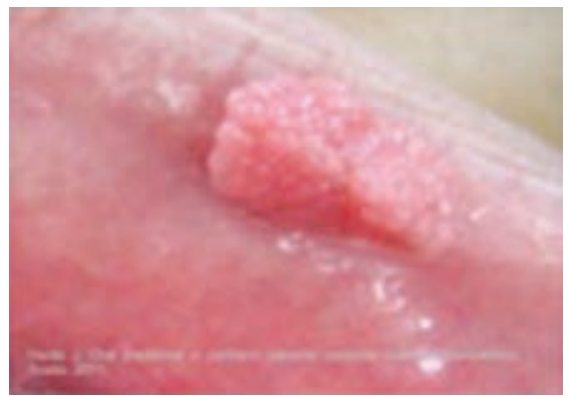

Papiloma

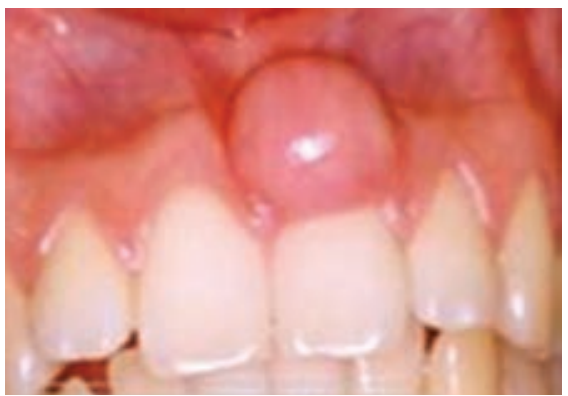

Fibroma osificante

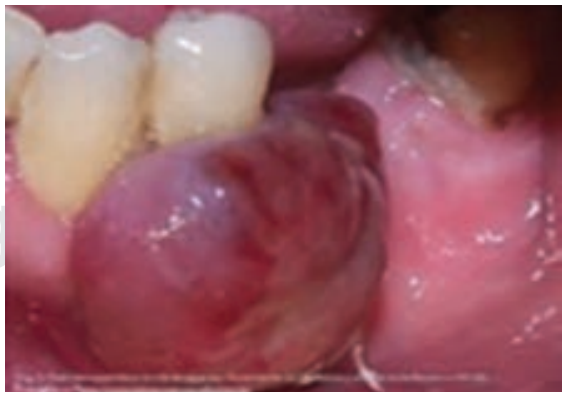

Granuloma periférico de células gigantes

Figura 1: Posibles diagnósticos diferenciales en presentación clínica para fibroma de fibroblastos gigantes. 

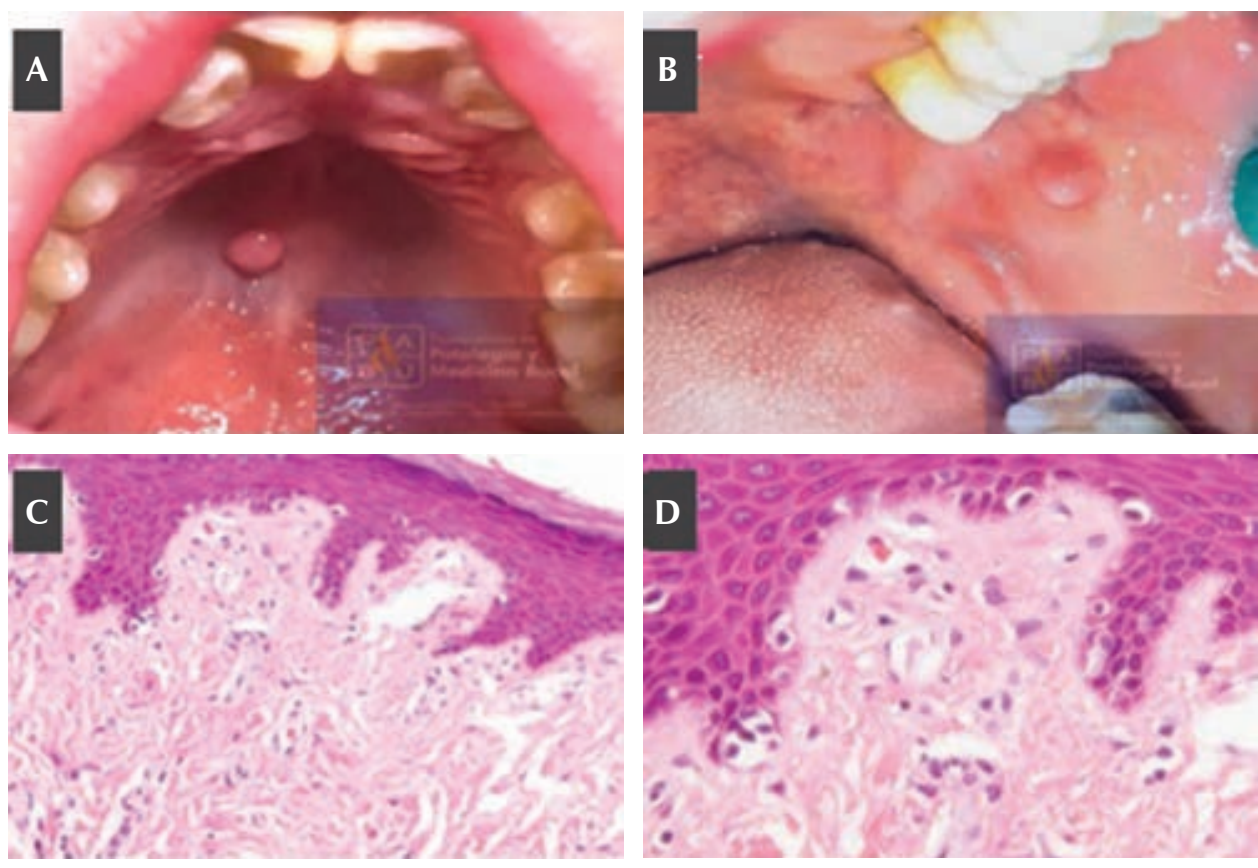

Figura 2:
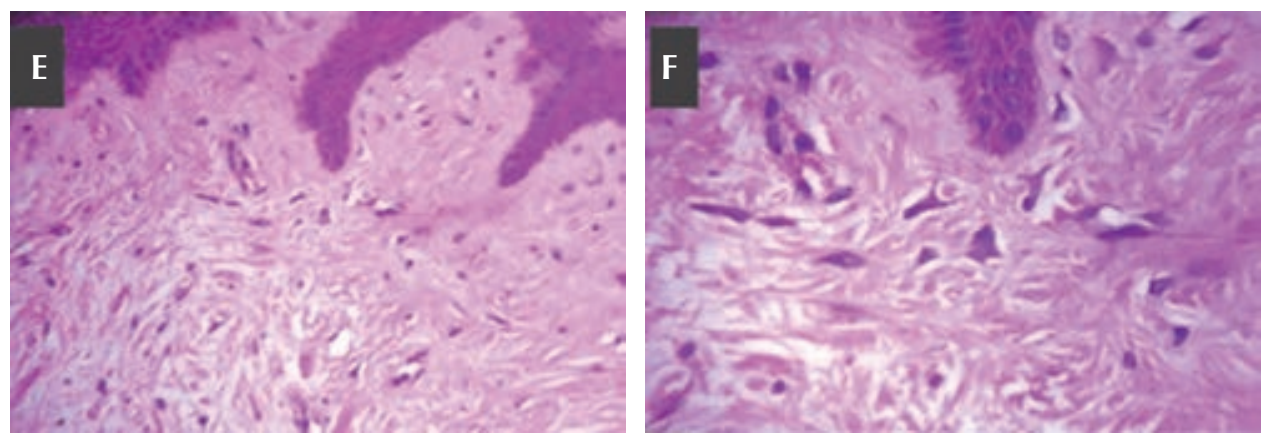

Características clínicas e histopatológicas. A) Pápula bien delimitada localizada en paladar duro, del mismo color que la mucosa adyacente de base sésil y superficie lisa. B) Pápula en mucosa bucal del lado izquierdo, a la altura del plano de oclusión. C-F) Tejido conectivo fibroso denso, con fibroblastos gigantes binucleados, de forma estrellada. Revestido por epitelio escamoso estratificado con melanina en capa basal y acantosis. Microscopio óptico Zeiss Axioskop 2. 10× y 40×. Fuente directa.

\section{DISCUSIÓN}

El FFG es poco frecuente, en este estudio representa $1.58 \%$ de 7,681 muestras diagnosticadas de 2004 a 2019, a comparación con Neville ${ }^{2}$ quien reporta que ésta representa aproximadamente de 2 a $5 \%$ de todas las biopsias bucales de tejido fibroso y de 0.4 a $1 \%$ del total de resultados histopatológicos.

Los resultados indican un amplio rango de edad de uno a 84 años, Sabarinath ${ }^{8}$ reporta un rango de seis a 67 años; la edad promedio obtenida es de 38 años, mientras que las publicaciones de Magnusson ${ }^{7}$ registran un promedio de 27.7 años y Sabarinath ${ }^{8} 29$ y 39 años.

El mayor número de casos se presentó en la segunda década de vida para el sexo masculino, en la quinta para el femenino y para ambos sexos en la segunda en comparación con la literatura que establece la presencia de la lesión en las primeras tres décadas de vida con $60 \%$ de acuerdo con Weathers, ${ }^{1}$ Houston, ${ }^{11}$ Campos $^{12}$ y Neville ${ }^{2}$ mientras que Bakos ${ }^{17}$ y $\mathrm{Kuo}^{9}$ refieren un mayor número de casos en la tercera y quinta década.

En los casos obtenidos, la edad más temprana en la que se presentó fue de 16 meses, con el diagnóstico diferencial de épulis congénito, Vergotine ${ }^{24}$ menciona en su estudio que la edad más baja en la que se ha reportado es de 18 meses. En este estudio el FFG tuvo predilección por el sexo femenino, se registró una razón de 1.6:1 mujer a hombre, datos que coinciden con Weathers, ${ }^{1}$ Houston, ${ }^{11}$ Campos $^{12} y$ Neville ${ }^{2}$ quienes reportan una razón 1.5:1 mujer a hombre.

Debido a su apariencia clínica y parecido a otras entidades, el diagnóstico enviado con más frecuencia es hiperplasia fibrosa, seguido de fibroma, papiloma, granuloma piógeno, mucocele, etcétera. Sólo uno de los 122 casos, en un periodo de 15 años, fue enviado como 
FFG, lo que indica que el profesional tiene conocimiento de la lesión, sus características, la edad y sexo en que se presenta con más frecuencia y su localización, ya que el caso fue de un paciente femenino de 20 años con aumento de volumen en la encía mandibular a la altura del canino inferior derecho. Los diagnósticos diferenciales más enviados de acuerdo con Houston, ${ }^{11}$ Gnepp ${ }^{3}$ y Shafer ${ }^{25}$ son: papiloma, fibroma, hiperplasia fibrosa y fibroma osificante periférico.

En los casos estudiados, la localización más frecuente fue en el dorso de la lengua (46\%); encía (15\%); paladar (15\%); mucosa yugal (13.3\%); mucosa labial (5\%); fondo de saco $(3.3 \%)$ y comisura labial $(1.6 \%)$, a diferencia de la literatura que indica como sitio más común la encía y en segundo lugar la lengua; cabe mencionar que sólo 60 casos de los 122 reportaron la localización de la lesión, lo cual equivale a $49.1 \%$.

\section{CONCLUSIONES}

Debido a que se presenta en un amplio rango de edad, es importante realizar correctamente la exploración

\begin{tabular}{lcr}
\multicolumn{3}{c}{ Tabla 1: Diagnósticos presuntivos en 120 } \\
casos de fibroma de fibroblastos gigantes (FFG). \\
\hline Diagnóstico clínico & $n$ & $\%$ \\
\hline Hiperplasia fibrosa & 44 & 36.06 \\
Fibroma & 26 & 21.31 \\
Papiloma & 11 & 9.01 \\
Fibroma de fibroblastos gigantes & 1 & 0.81 \\
Fibroma osificante periférico & 1 & 0.81 \\
Mucocele & 2 & 1.63 \\
Granuloma piógeno & 3 & 2.45 \\
Papila gustativa hipertrófica & 1 & 0.81 \\
Neuroma traumático & 1 & 0.81 \\
Granuloma periférico de células gigantes & 1 & 0.81 \\
Épulis congénito & 1 & 0.81 \\
Agrandamiento gingival & 1 & 0.81 \\
Fibrosis & 1 & 0.81 \\
Hiperplasia fibrosa vs fibroma & 1 & 0.81 \\
Hiperplasia fibrosa vs papiloma & 1 & 0.81 \\
Hiperplasia fibrosa vs granuloma piógeno & 2 & 1.63 \\
Fibroma vs papiloma & 2 & 1.63 \\
Fibroma vs displasia fibrosa & 1 & 0.81 \\
\hline De los 122, 101 fueron enviados con el diagnóstico clínico. Fuente directa.
\end{tabular}

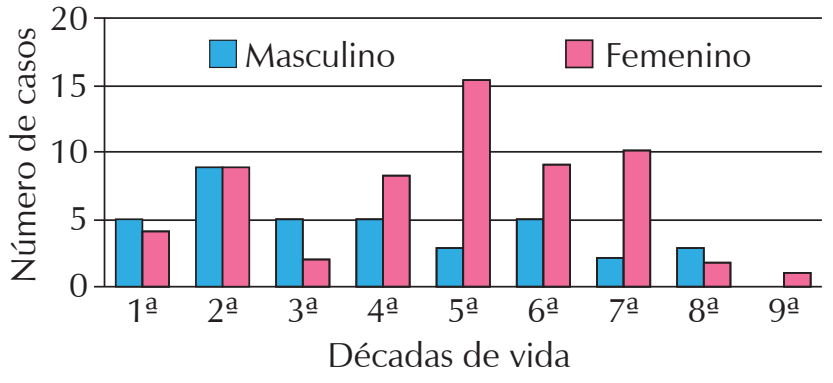

Figura 3: Número de casos presentes en cada década de vida de ambos sexos. En la segunda década de vida se presentó el mayor número de casos con $18.4 \%$ para los dos sexos, para el femenino en la quinta y para el masculino en la segunda. No se presentó ningún caso del sexo masculino en la novena década. Fuente directa.

bucal desde los primeros meses de vida en adelante. La importancia del conocimiento de esta lesión es que al parecerse clínicamente a otras patologías de tejido fibroso el odontólogo debe tener presente al FFG como posible diagnóstico diferencial, el cual se confirmará con el estudio histopatológico, por lo tanto, toda biopsia debe ser estudiada para su diagnóstico y tratamiento adecuado.

\section{REFERENCIAS}

1. Weathers DR, Callihan MD. Giant-cell fibroma. Oral Surg Oral Med Oral Pathol. 1974; 37 (3): 374-384.

2. Neville B. Oral and maxillofacial pathology. 4th ed. St Louis, Missouri: Elsevier; 2016.

3. Gnepp R. Diagnostic surgical pathology of the head and neck. 2nd ed. Philadelphia, PA, USA: Saunders Elsevier; 2009.

4. Regezi JA, Courtney RM, Kerr DA. Fibrous lesions of the skin and mucous membranes which contain stellate and multinucleated cells. Oral Surg Oral Med Oral Pathol. 1975; 39 (4): 605-614.

5. Reibel J. Oral fibrous hyperplasias containing stellate and multinucleated cells. Scand J Dent Res. 1982; 90 (3): 217-226.

6. Savage NW, Monsour PA. Oral fibrous hyperplasias and the giant cell fibroma. Aust Dent J. 1985; 30 (6): 405-409.

7. Magnusson BC, Rasmusson LG. The giant cell fibroma. A review of 103 cases with immunohistochemical findings. Acta Odontol Scand. 1995; 53 (5): 293-296.

8. Sabarinath B, Sivaramakrishnan M, Sivapathasundharam B. Giant cell fibroma: A clinicopathological study. J Oral Maxillofac Pathol. 2012; 16 (3): 359-362.

9. Kuo RC, Wang YP, Chen HM, Sun A, Liu BY, Kuo YS. Clinicopathological study of oral giant cell fibromas. J Formos Med Assoc. 2009; 108 (9): 725-729.

10. Woo S. Oral pathology: a comprehensive atlas and text. 2nd ed. Philadelphia: Elsevier; 2017.

11. Houston GD. The giant cell fibroma. A review of 464 cases. Oral Surg Oral Med Oral Pathol. 1982; 53 (6): 582-587.

12. Campos E, Gomez RS. Immunocytochemical study of giant cell fibroma. Braz Dent J. 1999; 10 (2): 89-92. 
13. Okamura K, Ohno J, Iwahashi T, Enoki N, Taniguchi K, Yamazaki J. Giant cell fibroma of the tongue: Report of a case showing unique s100 protein and HLADR immunolocalization with literature review. Oral Med Pathol. 2009; 13: 75-79.

14. Sonalika WG, Sahu A, Deogade SC, Gupta P, Naitam D, Chansoria $\mathrm{H}$ et al. Giant cell fibroma of tongue: understanding the nature of an unusual histopathological entity. Case Rep Dent. 2014; 2014: 864512.

15. Odell EW, Lock C, Lombardi TL. Phenotypic characterisation of stellate and giant cells in giant cell fibroma by immunocytochemistry. J Oral Pathol Med. 1994; 23 (6): 284-287.

16. Jimson S, Jimson S. Giant cell fibroma: a case report with immunohistochemical markers. J Clin Diagn Res. 2013; 7 (12): 3079-3080.

17. Bakos LH. The giant cell fibroma: a review of 116 cases. Ann Dent. 1992; 51 (1): 32-35.

18. Holt DJ, Grainger DW. Multinucleated giant cells from fibroblast cultures. Biomaterials. 2011; 32 (16): 3977-3987.

19. Kritsilis M, Rizou SV, Koutsoudaki PN, Evangelou K, Gorgoulis VG, Papadopoulos D. Ageing, cellular senescence and neurodegenerative disease. Int J Mol Sci. 2018; 19 (10): 2937.

20. Cho MI, Garant PR. Formation of multinucleated fibroblasts in the periodontal ligaments of old mice. Anat Rec. 1984; 208 (2): 185-196.
21. Mighell AJ, Robinson PA, Hume WJ. PCNA and Ki-67 immunoreactivity in multinucleated cells of giant cell fibroma and peripheral giant cell granuloma. J Oral Pathol Med. 1996; 25 (5): 193-199.

22. Shapira M, Akrish S. A 6-year-old girl with a lesion on the tongue. Giant cell fibroma of tongue. Pediatr Ann. 2011; 40 (2): $71-74$.

23. Uloopi KS, Vinay C, Deepika A, Sekhar RC, Raghu D, Ramesh T. Pediatric giant cell fibroma: an unusual case report. Pediatr Dent. 2012; 34 (7): 503-505.

24. Vergotine RJ. A giant cell fibroma and focal fibrous hyperplasia in a young child: a case report. Case Rep Dent. 2012; 2012: 370242 .

25. Shafer W, Hine M, text LB. A textbook of oral pathology. 6th ed. Philadelphia, PA, USA: Elsevier; 2009.

\section{Correspondencia: \\ Mtra. Beatriz Catalina Aldape Barrios \\ E-mail: patobu1@hotmail.com}

Conflicto de intereses: Los autores declaran no tener ningún conflicto de intereses. 